backward masking function in vision. Psychonomic Science, 1965, 2, 75-76.

WEISSTEIN, N., JURKENS, $r$., \& ONDERISIN,

T. Effect of forced choice vis magnitude-estimation measures on the waveforms of metacontrast functions. Journal of the Optical Society of America, 1970, 60, 978-981.

\section{Interval estimation as a function of constant and interrupted stimulation*}

\author{
GERALD LONG and SUCHOON MO \\ The University of Detroit, Detroit, Mich. 48221
}

The present study investigated the relationship between a temporal interval's perceived length and the amount of stimulus and stimulus change within that interval. In three separate tests, completely filled intervals were found to be significantly overestimated by the $\mathrm{Ss}$ in comparison with empty intervals. In contrast to this, interrupted or divided intervals were underestimated.

There appears to be some confusion over the effects of stimulation upon short temporal estimations. It is generally agreed that, in comparison with an "empty" interval, a completely "filled" temporal interval (i.e., some stimulus duration) is usually overestimated by S (Meumann, 1896; Fraisse, 1963). However, the effects of "interrupting" or "dividing" temporal intervals are still somewhat in question. Following Hall \& Jastrow (1886), Fraisse (1961, 1963, 1965) has attempted to draw an analogy between Uppel's illusion of visual extent, in which a divided line appears longer than an unbroken line, and the interrupting of a

*The authors wish to thank Mr. Jerome Heckenmueller and Mr. Robert Novelly for their aid in analyzing the data and Miss Cathy McIvor for her help in its collection. temporal interval with various stimuli. Such an interrupted or broken interval should then appear longer or be overestimated by $\mathrm{S}$ when compared to an empty interval of objectively the same length. Other researchers, however, have found opposite results in their studies, results perhaps more in line with the common-sense notion of change making time appear to pass more quickly (Benussi, 1917; Roelofs \& Zeeman, 1949, 1951; Hawkins \& Meyer, 1965). The present study attempts to clarify this area in regard to the effects of both constant and interrupted stimulation upon $\mathrm{S}$ 's short temporal estimations.

\section{METHOD}

The Ss were 13 male and 12 female undergraduates at the University of Detroit. The apparatus employed were a Lafayette reaction-time machine, an
Industrial Timer Corporation stopclock, a buzzer, and a telegraph key. By depressing a button, E could both start the timer and present a light of moderate intensity to $\mathrm{S}$. $S$ had before him a button which, by depressing, would terminate the light stimulus and stop the timer. $E$ also controlled a buzzer by means of a telegraph key, thereby enabling him to present the buzzing sound at any point during any of the trials. Finally, all trials were run in a semidark and sound-deadened room.

Test 1

Each of 15 Ss was initially run through 10 practice trials in which $\mathrm{E}$ presented the light and, after $3.25 \mathrm{sec}$, instructed $S$ to terminate it by pressing his button. This was done to acquaint $S$ with the approximate length of a $3.25-\mathrm{sec}$ interval. Forty test trials now followed in which $S$ was instructed to "pay attention" to the light before him. When it went on, he was to estimate $3.25 \mathrm{sec}$ and then turn it off by pressing the button. There was approximately a 5-sec intertrial interval. Randomly mixed within the 40 trials were four different auditory conditions (10 trials of each), which differed as to the amount of buzzer presented by $E$ during the interval. On any particular trial, $E$ presented the buzzer once (B1) or twice (B2) or continuously (BC) or not at all (NB). S's temporal productions of his estimate of a 3.25 -sec light duration were recorded by $E$ from the stopclock after each trial. $\mathrm{S}$ was instructed to sit quite still and not to use any form of rhythmical tapping in estimating the duration.

Test 2

The instructions given $S$ and the procedure followed in Test 2 were almost identical with those of Test 1 , except that the length of the light duration to be

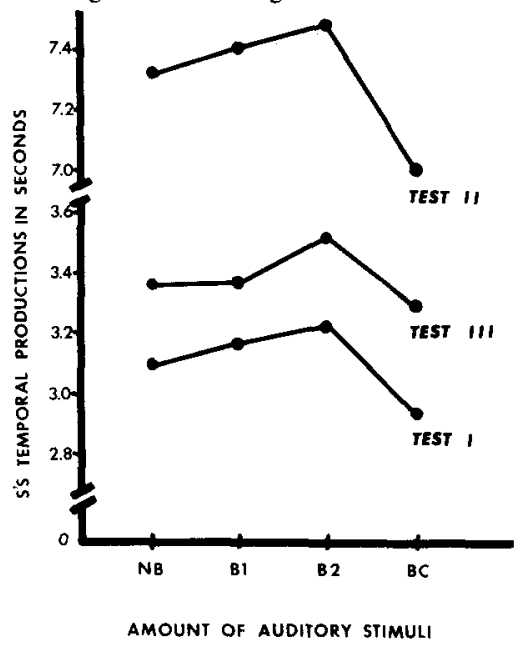

Fig. 1. The effects of varying amounts of auditory stimuli upon S's temporal estimations. 


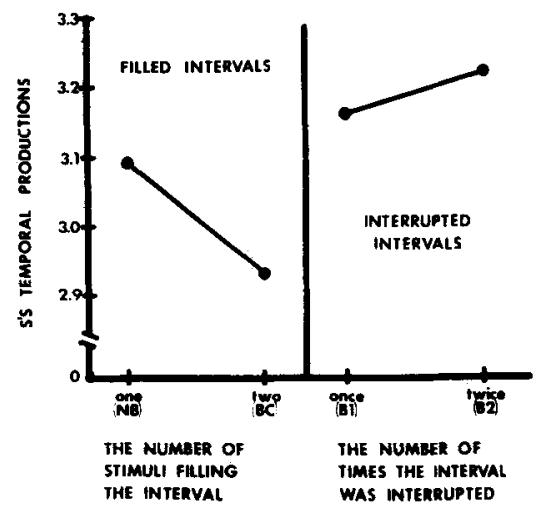

Fig. 2. The effects of the type and degree of stimulation within the interval on S's productions in Test 1.

estimated by $S$ was changed. After 10 practice trials with a $7.00-\mathrm{sec}$ light duration, $\mathbf{S}$ was instructed to terminate the light after $7.00 \mathrm{sec}$ rather than $3.25 \mathrm{sec}$ as in Test 1 . This test was run approximately 1 week after Test 1 , using 10 Ss who had participated in the earlier test.

Test 3

A second group of 10 Ss was run through the experiment producing estimates of 3.25 -sec intervals, but without any light stimulus. Each $S$ was instructed to listen for the "click" made by the start of the reaction-time machine. After hearing the click, S was to wait $3.25 \mathrm{sec}$ and then press his button. No light stimulus was presented in any of these trials. In regard to the four auditory conditions, Test 3 was identical with Test 1.

\section{RESULTS}

Presented graphically in Fig. 1 are the overall results of the three tests. It can be seen that, in general, the effects of the varying amounts of auditory stimuli within each test were very similar. Approximately the same data trend is revealed in all three curves.

\section{Test 1}

The up-down character of the graph in Fig. 1 may at first appear confusing, unless the data are analyzed in terms of a possibly fundamental difference existing within the four auditory conditions. This possibility exists in that the first and last auditory condition (NB and $\mathrm{BC}$ ) were basically different from the two middle conditions in terms of stimulus quality. Both the first and last condition were actually completely "filled" intervals of time [filled with light only (NB) or with light and buzzer $(B C)]$, while the other two conditions were auditorily "interrupted" or divided intervals in the presence of the constant light stimulus. In Fig. 2 it can be seen that, graphed with this distinction kept in mind, two different and opposite effects appear to result from filling vs interrupting the intervals. The effect of filiing an interval was a sıgnificant underproduction $(\mathrm{p}<.01)$ by $\mathrm{S}$, in comparison with interrupting the interval. An unexpected, but interesting, result was that filling the interval even more led to further significant underproduction $(p<.01)$, whereas interrupting more to more overproduction $(\mathrm{p}<.01)$.

\section{Test 2}

As evidenced in Fig. 1, the same apparent relationships are also clearly present in Test 2, which simply employed longer $(7.00 \mathrm{sec})$ temporal productions than Test 1.

\section{Test 3}

The real interest in Test 3 lies in its comparison with Test 1 , from which it differed solely in the absence of the light stimulus that had been present in the earlier test. In comparison with the first test, there was a complete upward shift in the length of the productions in Test 3 under all four auditory conditions (Fig. 1). The difference between these two tests, which used independent Ss, was also significant $(p<.05)$. The effects of the varying auditory conditions within Test 3 itself were very similar to those in Tests 1 and 2 (Fig. 3).

\section{DISCUSSION}

In all three of the tests in the present experiment, there has been clear support for the contention that a filled interval of time is overestimated in comparison with an unfilled or partially filled (interrupted) interval. As previously described by Bindra \& Waksberg (1956), with the method of production as employed in the present experiment, an underproduction actually represents a subjective overestimation of the interval by $S$ and vice versa. Hence, the constant underproduction within each test of the fourth auditory condition (BC), in comparison with the first condition (NB), supported those earlier studies that found filled intervals to be comparatively overestimated. An unexpected finding was that the more the interval was filled, the more it was overestimated. The significant difference between Tests 1 and 3 was further 'support for the singular overestimating effect of filling a short interval of time. The difference between the two tests could only have resulted from the lack of the light stimulus filling the interval in Test 3. As a result, Test 3 was overproduced (or underestimated) in comparison with Test 1.

In regard to interrupting or dividing the temporal intervals, the fact that both the first and fourth condition were consistently and significantly underproduced in comparison with the two middle conditions supports those studies which found divided intervals to be comparatively underestimated.

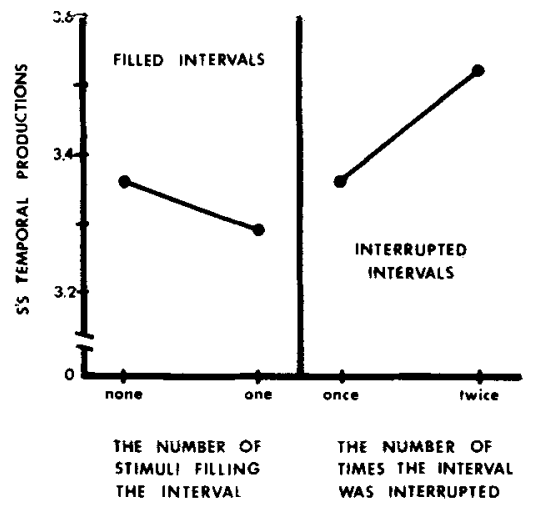

Fig. 3. The effects of the type and degree of stimulation within the interval on S's productions in Test 3.

Furthermore, it was also found that the more the interval was interrupted, the shorter it appeared (i.e., the more it was overproduced). These findings concerning divided intervals are in contrast to Fraisse's and apparently dictate against his attempts to apply Oppel's illusion to temporal situations. However, as indicated by Bindra \& Waksberg (1956) and others, in this area of time perception supposed differences have sometimes simply been the result of terminology differences. Because of the unusual equating of underproductions with subjective overestimations of the intervals in the present experiment, such might possibly be the case here also.

\section{REFERENCES}

BENUSSI, V. Versuche zur Analyse taktil erweckter Scheinbewegungen. Archiv für die gesamte Psychologie. 1917, 36, 59-135. (Cited by Paul Fraisse in The psychology of time.)

BINDRA, D. \& WAKSBERG, H. Methods and terminology in studies of time estimation. Psychological Bulletin, 1956, 53, 155-159.

FRAISSE, P. Influence of duration in frequency of changes in time estimation. Anée Psychologique, 1961, 61, 323-339.

FRAISSE, P. The psychology of time. New York: Harper \& Row, 1963.

FRAISSE, P. The temporal Oppel-Kundt illusion, or the influence of the frequency of stimulation on the perception of time. Psychologie Francaise, 1965, 10, 352-358.

HALL, G. S., \& JASTROW, J. Studies of thy thm. Mind, 1886, 11, 55-62.

HAWKINS, N., \& MEYER, M. Time perception of short intervals during finished, unfinished, and empty task situations. Psychonomic Science, 1965, 3, 473-474.

MEUMANN, E. Beitrage zur Psychologie des Zeitbewussteins. Philosophische Studien, $1896,12,128-254$. (Cited by Paul Fraisse in The psychology of time.)

ROELOFS, O., \& ZEEMAN, W. P. C. The subjective duration of time intervals. I. Acta Psychologica, 1949, 6, 126-177.

ROELOFS, O., \& ZEEMAN, W. P. C. Influence sequences of optical stimuli on the estimation of duration of a given interval of time. Acta Psychologica, 1951, 8, 89-128. 